\title{
TRICUSPID ATRESIA AND ITS PROGNOSIS WITH AND WITHOUT SURGICAL TREATMENT
}

\author{
BY \\ MAURICE CAMPBELL \\ From the Cardiac Department, Guy's Hospital, and the Institute of Cardiology
}

Received June 121961

Tricuspid atresia is one of the less common forms of congenital heart disease, but it is by no means rare and Abbott (1936) included 16 examples among her 1000 cases. The diagnosis of tricuspid atresia was made in $31(5 \%)$ of the first 670 patients with cyanotic congenital heart disease that I saw, mainly at Guy's Hospital, in 1947-51 (Campbell, 1953); and Wood (1956) found it in 1.5 per cent of his 900 cyanotic and acyanotic cases. The incidence was nearly equal in each sex in both series: in mine (increased later to 40 cases) 22 were male and 18 female. More than two-thirds were under 10 years of age, 32 per cent being aged 0-4 years, though in general few infants under 3 years were seen, 40 per cent being between 5-9 years, 18 per cent $10-14$ years, and only 10 per cent 15 years or more. Obviously the mortality is high, even after infancy, and it was estimated at 30 per cent within five years of their being seen (Campbell, 1953). Only among patients with pulmonary atresia and those with transposition of the great vessels was the mortality in the same high range.

It seemed at first that operation was of less benefit to them than to patients with Fallot's tetralogy, so relatively few were admitted for investigations and consideration of surgical treatment, which must at present take the form of subclavian-pulmonary or other anastomotic operations. The main object of this paper is to discuss the natural prognosis and how far this was improved by operation in 12 patients.

\section{Diagnosis and Clinical Features}

The clinical features of two cases of tricuspid atresia were described by Taussig in 1936 and of another by Brown in the same year, all these with necropsies. The triad of central cyanosis, a diminutive right ventricle, and left axis deviation, often with a large P wave in lead II, led to its clinical recognition becoming more frequent, though this was not at all widespread till ten years later when the possibility of surgical treatment made it more important.

The symptoms are much the same as in other forms of cyanotic congenital heart disease. More than half of our patients squatted and I have an impression that in tricuspid atresia squatting indicates a greater degree of disability and cyanosis than it does in Fallot's tetralogy. The physical signs are not distinctive. In some of our patients, the systolic murmur was heard and the thrill felt rather over to the right, so that the possibility of aortic stenosis was sometimes considered at an early stage.

Generally, therefore, the diagnosis is not suspected before the electrocardiogram shows left axis deviation and left ventricular preponderance. Radioscopy provides the most important confirmation and this has been fully discussed by Astley et al. (1953). The heart was enlarged in 12 of their 16 cases, though it was only slightly enlarged in most of the cases of Brown et al. (1956). We have often found it of considerable size: the early films are not now available but we have measurements of rather over half our cases. The heart was normal-sized in 13 per cent, slightly enlarged (c.t.r., $50-54 \%$ ) in 27 per cent, considerably enlarged (c.t.r., 55-59\%) in 33 per cent, and greatly enlarged (c.t.r., $60-67 \%$ ) in 27 per cent. 
Most of the films in the antero-posterior position show a characteristic feature, though probably it is no more than the relative absence of the right ventricle-a point that has been emphasized for the left antero-oblique position by Taussig. The heart seems tilted, from under-development of the right side and over-development of the left side. It is well shown in Fig. 1 and 2. The appearance is perhaps the absence of the expected right-sided enlargement when there is so much on the left side, though sometimes a large right atrium obscures this feature.
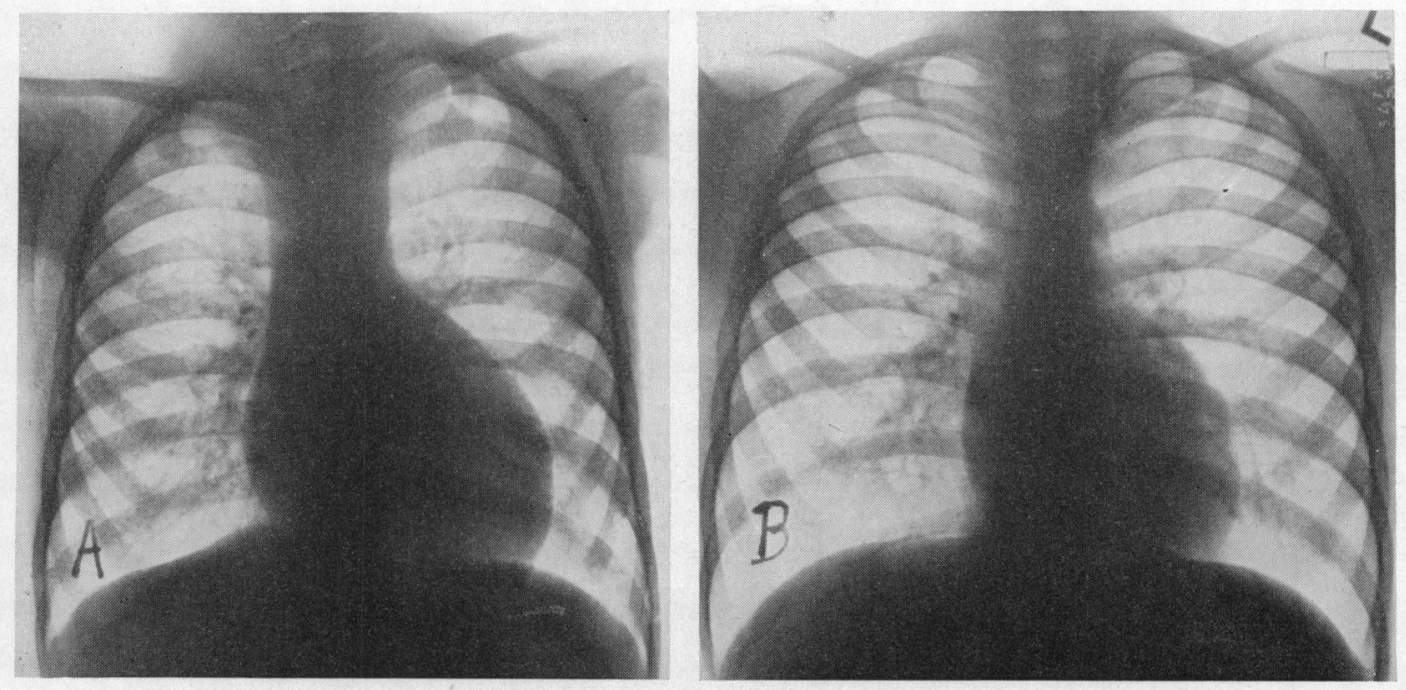

Fig. 1.-Teleradiograms from two boys, aged 8 and 10, with tricuspid atresia, who did well for at least six years after subclavian-pulmonary anastomosis but have since died. (A) Case 1: c.t.r. 54 per cent $(11 \cdot 0 / 20 \cdot 4$ $\mathrm{cm}$.) (B) Case 6: c.t.r. 46 per cent $(10 \cdot 5 / 24 \mathrm{~cm}$.).
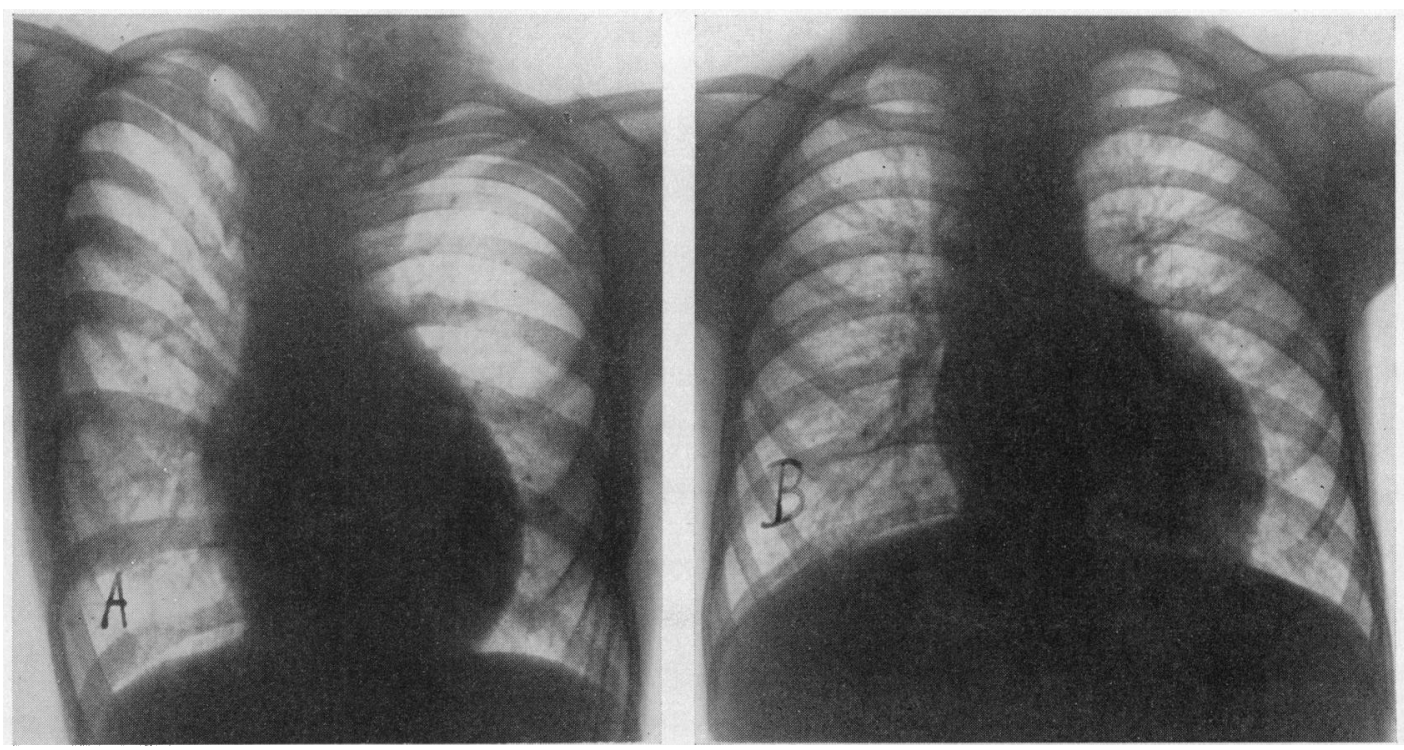

FIG. 2.-Teleradiograms from two patients with tricuspid atresia. (A) From a girl, aged 14, with severe kyphoscloliosis, who has done well for six years (c.t.r. $58 \% ; 12.0 / 20.5 \mathrm{~cm}$.) Case 20 . (B) From a boy, aged 9, who did well until his death from a cerebral abscess (c.t.r. $54 \% ; 9 \cdot 5 / 17 \cdot 7 \mathrm{~cm}$.) Case 17. 
There does not seem to be any tendency for the aortic arch to be right-sided as it is in so many cases of Fallot's tetralogy. It was in the normal position in all our 24 cases where we have a record of the position, and no right-sided aortic arch was reported in any of the 45 cases of Edwards and Burchell (1949).

Left axis deviation and left ventricular preponderance are almost constant and were seen in almost all our cases, but may of course occur in other conditions. Neill and Brink (1955), comparing the electrocardiograms in tricuspid atresia and single ventricle, found left axis deviation was present in 24 of the 28 cases of tricuspid atresia with necropsy, and left ventricular preponderance in 20 of the 21 with precordial leads, but also in 3 of the 7 cases of single ventricle.

Evidence of right atrial hypertrophy was found in the $P$ wave of 23 of the 28 cases of Neill and Brink (1955). Brown et al. (1956) found tall peaked P waves in only 2 of their 8 cases. Vela et al. (1958) found large bifid P waves in leads I and II in 15 of their 19 cases, indicating enlargement of both atresia with asynchronous contraction. In our cases, the $\mathrm{P}$ wave in one or more leads, usually lead II, was more often broad than narrow and pointed; but even when it was broad, the right atrial component was generally larger and pointed (Fig. 3 and 4). In 22 cases, the $P$ wave was of normal size in 3 , from 2.5 to $3.9 \mathrm{~mm}$. in 3 , from $4.0-5.9 \mathrm{~mm}$. in 12 , and larger than this in $4(6,6,7$, and $8 \mathrm{~mm}$.).
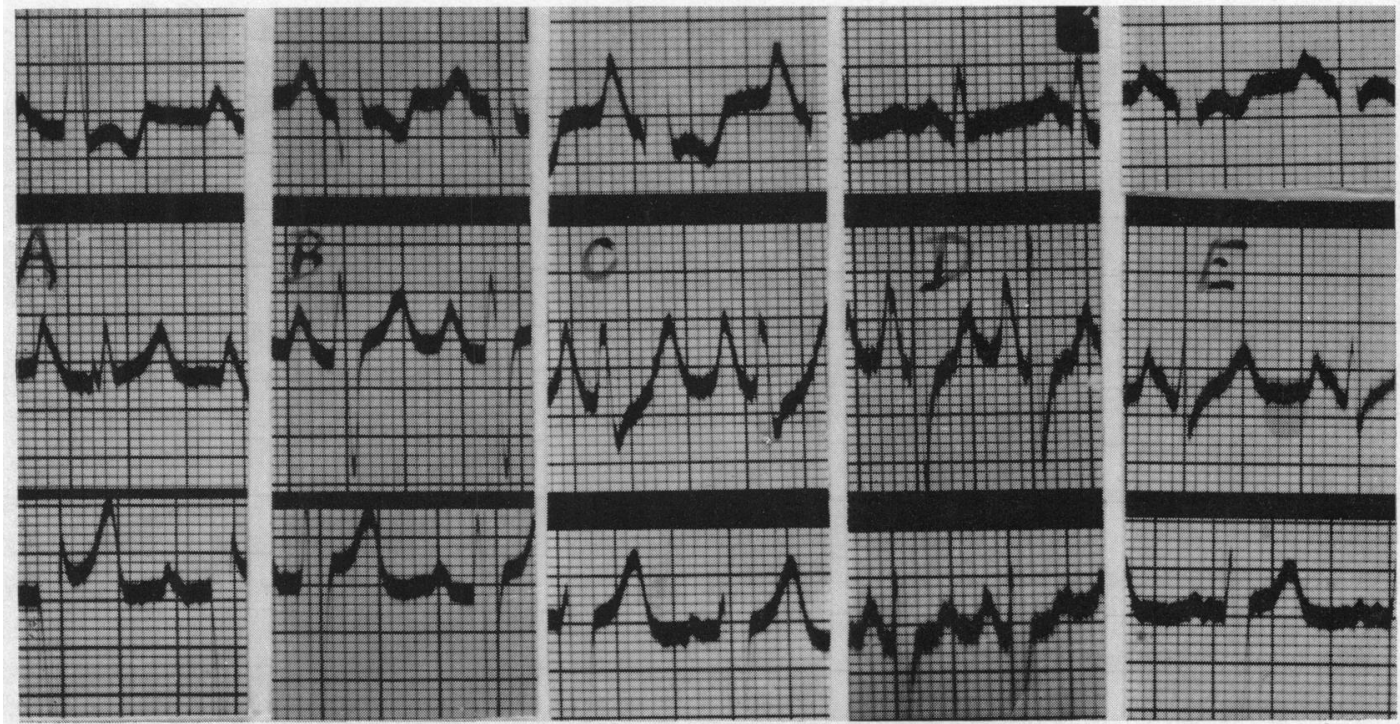

FIG. 3.-Standard leads with large $P$ waves in lead II, and sometimes in lead I, from five patients with tricuspid atresia who have died. All show left axis deviation. (A) and (B) Large broad P II, with notching just visible on the downstroke. Diagnosis confirmed by necropsy in both. Cases 6 and 23 . (C) and (D) Exceptionally large pointed $P$ waves in lead II (7 and $8 \mathrm{~mm}$.). Both patients died within three months, but the former death was unexpected and from meningitis. Cases 9 and 14. (E) A large broad notched P II from Case 8, who died with congestive heart failure ten months after operation.

A clinical diagnosis that rests mainly on the left ventricular preponderance will prove wrong in some of the cases, and angiocardiography is of great value in reaching a final conclusion. The passage of blood from the right to the left atrium is shown clearly. Campbell and Hills (1950) demonstrated a clear area between the right atrium and left ventricle and called it the "right ventricular window": this was well seen in 7 of the 8 cases of Brown et al. (1956). Cardiac catheterization is not generally of much value except when it proves the diagnosis is wrong. The atrial septal defect was demonstrated in only about half our cases but generally is shown more often. The arterial $\mathrm{O}_{2}$ 


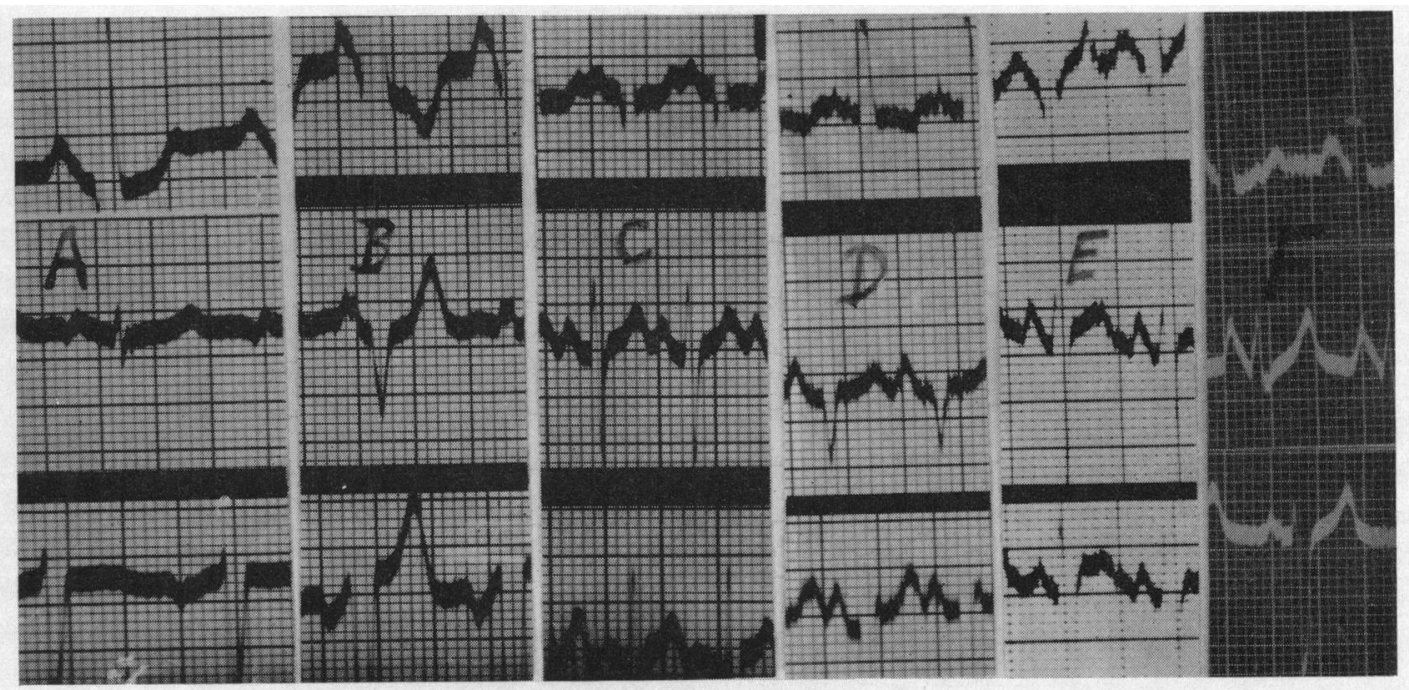

FIG. 4.-Standard leads with less striking $\mathbf{P}$ waves in lead II from six patients with tricuspid atresia. All show left axis deviation though there is a significant R III in (C). Cases 20 and 18 (A) and (C) have done well after operation but the other four patients have died.

(A) and (B). Large broad P waves in lead I with smaller ones in lead II. Cases 20 and $16 . \quad$ (C) to (F) Smaller $\mathbf{P}$ waves in lead II but still above normal limits. Cases 18, 19, 7, and 12.

saturation lay between 56 and 79 per cent in six consecutive cases, lower than the average of our cases of Fallot's tetralogy: generally the cyanosis and clubbing are moderately severe.

Even after angiocardiography, the diagnosis must sometimes remain in doubt, as is shown by later re-examination of some of the patient, even after an operation (e.g. Case 27) and sometimes only by necropsy. It would be more accurate if the title of this paper was the tricuspid atresia group: this forms a natural clinical group that must be considered together for some purposes.

\section{Prognosis Without Operation (22 Patients)}

To the original 31 patients, we have added 9 others seen later. Of these 40 patients, 12 had operations and are considered in the next section on surgical treatment, though they include two who were found at a later stage not to have tricuspid atresia. In addition to these two, 6 others were proved not to have tricuspid atresia, but their inclusion would hardly have changed the prognosis as four of them have died. They too are considered in a later section (see p. 707). The remaining 22 patients, presumed to have tricuspid atresia, are considered here: 16 of the 22 are known to have died, generally within a few years.

Patients who have Died (16 shown in Table I). In spite of this very heavy mortality of 73 per cent, the group seemed to be fairly representative of the cases of tricuspid atresia that survive infancy. Only the youngest and the oldest of the patients came to hospital because of their terminal illnessthe infant with cerebral symptoms (Case P052) and the woman of 23, who had always been severely disabled, with congestive failure of recent origin. The others were brought up to see if they could be helped by operation and did not seem much worse than the patients with Fallot's tetralogy seen at that time.

Nearly all were severely disabled and about an equal number were put into grades 3 and 4 , as was the case also among those with Fallot's tetralogy. Very few (much fewer than in Fallot's tetralogy) were put into grade 2, and two of these happened to have surgical treatment, though in one it was not till 9 years later. All were in grades 3 or 4 for cyanosis (about equal numbers in each) and all had well-marked clubbing of the fingers.

Some details of the 16 patients who died are shown in Table I. The hæmoglobin was most 
TABLE I

Sixteen Patients with Tricuspid Atresia who have Died

\begin{tabular}{|c|c|c|c|c|c|c|}
\hline Case No. & $\begin{array}{l}\text { Year } \\
\text { when } \\
\text { first } \\
\text { seen }\end{array}$ & $\begin{array}{l}\text { Sex } \\
\text { and } \\
\text { age }\end{array}$ & $\begin{array}{c}\text { Age } \\
\text { at } \\
\text { death }\end{array}$ & $\begin{array}{l}\mathbf{P} \\
\text { wave } \\
\text { size } \\
(\mathrm{mm} .)\end{array}$ & $\underset{\%}{\mathrm{Hb}}$ & Mode of death and other comments \\
\hline $3(0062)$ & 1947 & M6 & 7 & 6 & 140 & Attacks of unconsciousness. Died suddenly with \\
\hline $\begin{array}{r}7(\mathrm{P} 052) \\
9(\mathrm{P} 101) \\
10(\mathrm{P} 103)\end{array}$ & $\begin{array}{l}1947 \\
1947 \\
1947\end{array}$ & $\begin{array}{l}\text { F1 } \\
\text { M11 } \\
\text { M4 }\end{array}$ & $\begin{array}{r}1 \\
11 \\
6\end{array}$ & $\begin{array}{l}3 \\
7 \\
3\end{array}$ & - & $\begin{array}{l}\text { Whooping cougn } \\
\text { Died with ? cerebral abscess } \\
\text { Died with meningitis }\end{array}$ \\
\hline $\begin{array}{l}11(0154) \\
12(0180) \\
13(0211) \\
14(0296)\end{array}$ & $\begin{array}{l}1948 \\
1948 \\
1948 \\
1948\end{array}$ & $\begin{array}{l}\text { F2 } \\
\text { M7 } \\
\text { M6 } \\
\text { F2 }\end{array}$ & $\begin{array}{r}3 \\
8 \\
10 \\
3\end{array}$ & $\begin{array}{l}4 \\
5 \\
5 \\
8\end{array}$ & $\begin{array}{r}130 \\
146 \\
136 \\
84\end{array}$ & $\begin{array}{l}\text { Died in attack of unconsciousness } \\
\text { Severe; coarctation also } \\
\text { Died with "pneumonia" and hæmoptysis } \\
\text { Severe; }\end{array}$ \\
\hline $\begin{array}{l}15(0371)^{*} \\
16(0390)\end{array}$ & $\begin{array}{l}1949 \\
1949\end{array}$ & $\begin{array}{l}\text { M3 } \\
\text { F6 }\end{array}$ & $\begin{array}{r}6 \\
12\end{array}$ & $\begin{array}{l}5 \\
5\end{array}$ & $\begin{array}{l}150 \\
122\end{array}$ & $\begin{array}{l}\text { Attacks of unconsciousness. Died suddenly } \\
\text { Severe; ? pulm. atresia also. Hæmoptysis } 1 \text { yr. } \\
\text { before death }\end{array}$ \\
\hline $\begin{array}{l}19(\mathrm{P} 124) \\
21(0495)\end{array}$ & $\begin{array}{l}1949 \\
1950\end{array}$ & $\begin{array}{l}\text { F2 } \\
\text { F4 }\end{array}$ & $\begin{array}{l}3 \\
6\end{array}$ & $\begin{array}{l}4 \\
2\end{array}$ & $\overline{95}$ & $\begin{array}{l}\text { Many attacks of unconsciousness; died in one } \\
\text { Fairly severe }\end{array}$ \\
\hline $\begin{array}{l}22(0538) \\
23(0633)^{*} \\
25(\mathrm{HH} 1 \mathrm{P}) \\
26(0806)^{*}\end{array}$ & $\begin{array}{l}1950 \\
1951 \\
1952 \\
1952\end{array}$ & $\begin{array}{l}\text { F4 } \\
\text { F4 } \\
\text { M4 } \\
\text { F23 }\end{array}$ & $\begin{array}{r}6 \\
6 \\
4 \\
23\end{array}$ & $\begin{array}{l}4 \\
5 \\
3 \\
2\end{array}$ & $\begin{array}{r}130 \\
140 \\
134 \\
90\end{array}$ & $\begin{array}{l}\text { Severe. Died suddenly } \\
\text { Died S.B.E. and meningitis. Necropsy } \\
\text { ? Pulmonary atresia also } \\
\text { Died with congestive failure. Necropsy }\end{array}$ \\
\hline
\end{tabular}

* Patients with necropsy. The mode of death is given where it is known.

The case numbers in Tables I and II indicate the order in which the patients were first seen.

often between 130 and 146 per cent and averaged 136 per cent, excluding the three deeply cyanotic patients where it was under 100 per cent since they must have been very "anæmic." One reason for thinking they were severe cases is that the largest P wave (generally in lead II) averaged $4.4 \mathrm{~mm}$. in height. The larger $P$ waves seem to be an indication that the patient's condition is advanced and that he should be given the advantage of surgical treatment. In simple pulmonary stenosis $P$ waves of $5 \mathrm{~mm}$. or more have the same significance (Campbell, 1954), but here the explanation is more obvious and operation provides more direct relief.

The mode of death is given in Table I where it was known. Four patients had cyanotic attacks in which they went unconscious-a common complication in severe Fallot's tetralogy as well as in tricuspid atresia, and even more common in pulmonary atresia. All these four and one other died suddenly in such attacks. This was the most common mode of death, though cerebral abscess or meningitis occurred in three and two had hæmoptysis about the time they died: congestive heart failure was known to be the cause of death in only one of these patients though it was the cause of death in two others after operation (Cases 2 and 8).

The average duration of life of these 16 patients after they were first seen was less than 2 years and only two lived 4 years or more. In retrospect, it seems wrong that more of them did not have anastomotic operations, but in 1947-50, with the large number of patients waiting, those who seemed likely to obtain most benefit from operation had to be given preference, and I did not then realize how bad the prognosis for tricuspid atresia was. The boy, aged 11 (Case 9), was speically disappointing for he was not much disabled and could play a little cricket, and his meningitis was sudden and unexpected while he was waiting operation.

Necropsies. Only 3 of these 16 patients had necropsies and all were proved to have tricuspid atresia. Cases 15 and 26 will be mentioned only briefly as they have been fully reported by Scott (1955). In Case 15 the pulmonary trunk was transposed to the left ventricle and there was some subvalvular stenosis: the right ventricular cavity was little more than a slit in the muscle. In the 
other two there was no transposition of the great trunks. In Case 26, the ventricular septal defect (V.S.D.) measured 1.0 by $0.75 \mathrm{~cm}$., the right ventricle was very small, and there was some pulmonary infundibular stenosis. In all three there was an atrial septal defect, and this was largest and admitted the tips of four fingers in Case 26, the woman who lived for 23 years. In Case 23 we have no details of the size of the V.S.D. or of the type of obstruction. Meningococcal meningitis had been diagnosed by lumbar puncture during life and this was confirmed: there was no brain abscess but she had subacute bacterial endocarditis, and the V.S.D. was encircled by vegetations. A fourth necropsy is included in the surgical section (Case 6, see p. 706).

Patients who Survived. Only 6 of the 22 patients were living when we last heard about them. The first three, all boys between 8 and 18, are unusual in that they all got on so well for another six to ten years. The first (Case 29) has now had an operation but he has been left in this group because of the long follow-up before operation and the short time that has elapsed since it.

Case 29. A boy, aged 8, was moderately disabled and cyanosed. Investigations showed the presence of bilateral superior venæ cavæ and a right-to-left shunt through a large atrial septal defect and supported tricuspid atresia with a heart greatly rotated to the right. He could walk half a mile and remained much the same for 9 years until he developed subacute bacterial endocarditis. He made a good recovery and six months later had a subclavian-pulmonary anastomosis: he was greatly improved both in his capacity and colour, and has maintained this for 2 years.

Case 30. A boy, aged 12, had relatively few symptoms but examination and catheterization supported the diagnosis of tricuspid atresia. He has remained well for ten years: he is working regularly and notices little wrong except his cyanosis.

Case 31. A boy, aged 18, had left ventricular hypertrophy on the cardiogram and on radioscopy, but few symptoms and no obvious oligæmia of the lungs. Six years later he was working regularly in a laboratory and could spend an energetic day in the country shooting.

Cases 32-34. These three patients do not give us much information. One infant of a year was still getting on well after four years. The other two have not been traced, and, as one was an infant with frequent attacks of uncounsciousness and the other a mongol with hemiplegia, we think it unlikely that they are alive.

\section{Results of Surgical Treatment in 12 Patients}

There were 7 patients diagnosed as tricuspid atresia with a non-functioning right ventricle among the first 200 submitted to subclavian-pulmonary anastomosis (Campbell and Deuchar, 1953), and 5 more have had an operation since. All these 12 survived the operation. This must be good fortune as it cannot be safer than the same operation for Fallot's tetralogy, and is probably more dangerous since the patients are generally more disabled and the malformations of the heart are even more complex. As will be seen from the notes that follow, Cases 4 and 27 were not examples of simple tricuspid atesia.

Details of our 12 patients are given in Table II. We are describing them in three groups: (1) 7 who are still doing well after seven to ten years; (2) 2 who did well for six years or more but then relapsed and died in the tenth and seventh years respectively (Cases 1 and 6); and (3) 3 who died within eighteen months of their operation, two from congestive heart failure (Cases 2 and 8 ) and one from a cerebral abscess (Case 17).

The results of operation were good, but perhaps not quite as good as those for Fallot's tetralogy. This might be expected since the malformations of the heart are more complex. All the patients were greatly improved for some time and more than half of them have maintained this for from 6 to 10 years. Only in Case 1, and this in the tenth year, has the anastomosis closed, but this must be a lasting hazard, as has been found after operations for Fallot's tetralogy (Campbell, 1958b).

Case 5 could hardly have done better and has maintained his exceptionally good result for more than ten years. Case 20, who was more disabled, has done nearly as well. These are the only two who have passed the age of going to work and both have been working regularly for some years. Case 24 seems as good and should make this grade soon, but a year ago she had an illness that caused some anxiety: she seems, however, to have made a complete recovery. Cases 4,18 , and 28 have maintained all their improvement for from six to eight years and Case 27 is still greatly improved. Even Cases 1 and 6 were much better for more than six years before they relapsed. 
TABLE II

Clinical Findings in Patients before and after Operation

\begin{tabular}{|c|c|c|c|c|c|c|c|c|}
\hline \multirow{2}{*}{$\begin{array}{l}\text { Case } \\
\text { No. }\end{array}$} & \multirow{2}{*}{$\begin{array}{l}\text { Sex } \\
\text { and } \\
\text { age }\end{array}$} & \multirow{2}{*}{$\begin{array}{l}\text { Year } \\
\text { of op. }\end{array}$} & \multicolumn{2}{|c|}{ Before op. } & \multicolumn{3}{|c|}{ Years after op. } & \multirow[t]{2}{*}{ Later follow-up } \\
\hline & & & c.t.r. & $\mathrm{Hb} . \%$ & Years & c.t.r. & $\mathrm{Hb} . \%$ & \\
\hline 1 & M8 & 1948 & 53 & 125 & 6 & 56 & 125 & $\begin{array}{l}\text { Lost ground 6th-8th year. Died 11th } \\
\text { year }\end{array}$ \\
\hline $4 \dagger$ & M9 & 1953 & 54 & 126 & 7 & 58 & 117 & $\begin{array}{l}\text { Little improvement for } 2 \text { years, then } \\
\text { improved and after } 7 \text { years still good }\end{array}$ \\
\hline 5 & M19 & 1948 & 40 & 144 & 4 & 45 & 112 & Ten years very well (c.t.r. 42: Hb. 125) \\
\hline 6* & M10 & 1950 & 43 & 145 & 4 & 46 & 130 & Lost ground 6th year. Died 7 th year \\
\hline 18 & M6 & 1953 & 59 & 142 & 4 & 55 & 103 & Eight years still good (c.t.r. 53: Hb. 100) \\
\hline 20 & F14 & 1951 & 58 & 128 & 6 & 62 & 112 & Ten years still good (c.t.r. $63 \%$ ) \\
\hline 24 & F8 & 1953 & 50 & 116 & 4 & 48 & 108 & $\begin{array}{l}\text { Seven years, some purpura and œdema of } \\
\text { ankles, but } 8 \text { years very well }\end{array}$ \\
\hline $27 \dagger$ & M5 & 1953 & 55 & 117 & 4 & 50 & 101 & $\begin{array}{l}\text { Seven years, improvement maintained } \\
\text { but } \mathrm{Hb} .126 \%\end{array}$ \\
\hline 28 & F5 & 1954 & 56 & 136 & 4 & 54 & 117 & Six years equally well but $\mathrm{Hb} .136 \%$ again \\
\hline
\end{tabular}

Patients who died early

\begin{tabular}{r|l|l|l|l|r|r|r|l}
\hline 2 & M4 & 1948 & 61 & 132 & $6 / 12$ & 69 & 109 & $\begin{array}{l}\text { Died congestive heart failure, 8 mo. after } \\
\text { Died congestive heart failure, 10 mo. after } \\
\text { Died cerebral abscess 18 mo. after }\end{array}$ \\
\hline M9 & M9 & 1950 & 63 & 125 & $8 / 12$ & 68 & 100 \\
\hline
\end{tabular}

* Diagnosis confirmed by necropsy.

$\dagger$ There was evidence that these were not cases of simple tricuspid atresia (see text).

There was rather less close correlation between the clinical improvement and the objective findings than there is after operations for Fallot's tetralogy. The heart generally became larger, as it nearly always does after a successful operation for Fallot's tetralogy, but not after some of the later operations (Cases 18, 24, and 28). The hæmoglobin percentage fell but generally remained above normal. It showed some tendency to rise again, even without any apparent loss in the clinical improvement, e.g., Cases 27 and 28.

\section{Great Improvement Maintained for Several Years (7 Patients)}

Case 4. A boy, aged 4, was moderately disabled and cyanosed (grade 3) with left ventricular preponderance, and a large broad $P$ wave of $4 \mathrm{~mm}$. At angiocardiography the blood appeared to pass from the right to the left atrium and quickly reached the small aorta. Catheterization was indecisive: bilateral superior venæ cavæ $\left(\mathrm{O}_{2}\right.$ sat., $\left.56 \& 60 \%\right)$ entered a large atrium $\left(\mathrm{O}_{2}\right.$ sat., $\left.63 \%\right)$ that was thought to be a right, rather than a common, atrium. The catheter entered a ventricle with a systolic pressure substantially the same as that of the systemic arteries and an arterial $\mathrm{O}_{2}$ saturation of 70 per cent, mid-way between that of the atrium $(63 \%)$ and the systemic arteries $(78 \%)$. Dr. Deuchar thought that it was a right ventricle and that the aorta arose from this, but it could have been a common ventricle.

His operation, when he was 9 , confirmed that he had a more complex lesion than tricuspid atresia. $\mathrm{He}$ had valvotomy for pulmonary stenosis: both atrial appendages were on the left side and there was some suggestion of a single ventricle. He did not seem much better a year after his operation, but then improved slowly and steadily, and was much better and able to do more after 7 years.

Case 5. A boy, aged 19, has done well for ten years and can walk four miles with ease instead of half a mile with difficulty before operation. His colour is greatly improved. His heart was very small before operation so that an increase in the cardiothoracic ratio from 39 to 46 per cent still leaves it small. As usual, this increase took place soon after operation and has not progressed. He is working as a warehouseman and on a recent holiday walked twelve miles - the best result after an operation for tricuspid atresia. $\mathrm{He}$ has been reported as an example of unilateral rib-notching (Campbell, 1958a, Fig. 2).

Case 18. A boy, aged 6, had the usual signs of tricuspid atresia and could walk only 200 yards. After operation he became much better and has maintained his improvement for eight years. He is still frail, but can now walk a mile: his heart has actually become smaller and his hæmoglobin percentage has fallen from 142 to 103 , though he is still cyanosed (grade 2). 
Case 20. A girl, aged 14, was not so severely disabled but had a larger heart and also kypho-scoliosis (Fig. 2A). She was much better after operation and could soon lead a normal quiet life. After three years her hæmoglobin was 112 instead of 128 per cent and her heart had not increased greatly (c.t.r. 58 to $62 \%$ ). After 10 years, she is just as well and leads a normal quiet life, doing regular secretarial work and playing table tennis: her heart is no larger.

Case 24. A girl, aged 8, was very frail and disabled but not very cyanosed (grade 2). She had left ventricular preponderance and P II was broad but only $2.5 \mathrm{~mm}$. in height. At her anastomotic operation, she was thought to have infundibular stenosis. A year after she was much better. In the seventh year she had an illness with purpura and swelling of her ankles, but blood cultures were negative. In the eigth year she was as well as ever, leading an active life at school and running about with her friends. Her heart had been of normal size and remained so. Her hæmoglobin had fallen from 116 to 108 per cent.

Case 27. A boy, aged 6, appeared to have fairly severe tricuspid atresia, with a large pointed P II, $4 \mathrm{~mm}$. high. Angiocardiography was thought to support the diagnosis as the diodone appeared to pass from the right to the left atrium, and thence to the left ventricle and aorta, with little filling of the pulmonary arteries and lungs. After subclavian-pulmonary anastomosis he was much better and maintained most of his improvement for 8 years.

Then, since he seemed unlikely to be able to earn a living after leaving school, his parents were anxious to know if more could be done. Selective angiocardiography now suggested that he had a V.S.D., pulmonary stenosis, and corrected transposition. The catheter passed through the right atrium and lay apparently above the V.S.D. as the injected material entered both ventricles. The ventricle on the right seemed from its shape and size to be a "left ventricle" and the pulmonary trunk arose from this, presumably with moderate pulmonary stenosis. The ventricle on the left was thought to be a "right ventricle" and the aorta arose from this. Some regurgitation of injected material from the ventricle on the right to the right atrium finally excluded tricuspid atresia which had been accepted without question up to this stage.

Case 28. A girl, aged 5, was severely disabled and cyanotic (grade 4) and could walk only 20 yards. I had made a diagnosis of tricuspid atresia when she was 2 years old and the cardiogram already showed left ventricular preponderance and a large pointed P II, $5 \mathrm{~mm}$. high. Three years after an anastomotic operation she was doing well at school and could walk two miles: she rarely squatted but was still deeply cyanosed. Her heart was a little smaller. After another three years she was equally well and active but her hæmoglobin which had fallen to 117 had risen to its original level of 136 per cent.

\section{Great Improvement for Several Years but Relapse and Subsequent Death (2 Patients)}

Case 1. A boy, aged 8, was extremely blue and became exhausted after walking 20 yards. He was at once improved by operation, but was so frail that he could not do much at first. With exercises he steadily improved for three years and could then run $\mathbf{5 0}$ yards or walk five miles and was leading a quiet life at school. There was not much increase in the size of the heart (c.t.r. 53 (Fig. 1A) to $56 \%$ ). He had grown 6 inches and put on $21 \mathrm{lb}$. in weight.

He continued as well for six years but then his ankles started to swell towards evening. This subsided with rest in hospital but his albumenuria, about 1 part per 1000, persisted. He never regained his earlier improvement and in the eight year became increasingly tired after an attack of rheumatism with swelling of several joints: no evidence of bacterial endocarditis was found. The continuous murmur was still the same, and his urine still contained albumen but few casts. It was not clear how much his deterioration was due to his heart and how much to his kidneys, but there was no evidence of chronic nephritis. In the tenth year he had lost all his improvement and complained of anginal pain: the continuous murmur could no longer be heard. He died suddenly with severe chest pain nearly 12 years after his operation. Several of our cyanotic patients have had unexplained albumenuria: it would be interesting to know if they have the type of renal changes that have been described by Spear (1960).

Case 6. A boy, aged 10, could walk only 100 yards. After operation he improved slowly and two years later he could walk a mile and attend an ordinary school: his cyanosis was somewhat less. There was not much increase in the heart size (Fig. 1B).

In the sixth year he lost some ground and generally went to school by car instead of walking, and in the next year he became worse and had attacks of hæmoptysis. His continuous murmur could still be heard but perhaps less easily. His cyanosis had, however, increased and the hæmoglobin, which had fallen from 131 to 118 per cent, had risen again to 134 per cent, with a red count of 13 million. He seemed unlikely to be able to work as a pharmacist and we were considering a second anastomosis, when he had some transient difficulty in speaking, with diplopia and numbness of the left side of the face, that were thought to be due to thrombosis of a basilar artery. When he had recovered a second operation was carried out on the right side, but he died three days later with bronchopneumonia.

Necropsy. The heart weighed $395 \mathrm{~g}$. The right atrium was dilated and hypertrophied with a large Eustachian valve. There was no tricuspid orifice but a large ostium secundum defect, measuring $20 \times 12 \mathrm{~mm}$. The left atrium, slightly dilated and hypertrophied, received the pulmonary veins normally, and the mitral 
valve ring was dilated. The left ventricle, much dilated and hypertrophied and 20-24 mm. thick, made up the greater part of the heart. The aortic valve was normal, but the aorta was hypoplastic.

The ductus arteriosus was closed and the bronchial arteries were not hypertrophied, so blood had reached the lungs only from the R.V. through the V.S.D. This was $3 \mathrm{~mm}$. in diameter and high in the septum and opened into a rudimentary right ventricle with a muscular wall only $3 \mathrm{~mm}$. thick. There was moderate infundibular stenosis, and a normal pulmonary valve. The pulmonary trunk rose from the small right ventricle, and the arteries were only slightly hypoplastic.

The old anastomosis was perfectly patent but its subclavian component $(14 \mathrm{~mm}$. in diameter) showed a low atheromatous plaque. The recent anastomosis also was satisfactory. The V.S.D. was ringed by pale brown vegetations on its right ventricular aspect: section showed these were covered by endothelium and were undergoing organization, and the bacilli seen on the surface were thought to be contaminants.

The lungs showed some bronchopneumonia and severe collapse secondary to widespread bronchiolitus. The liver was pale with some fatty changes. Externally the brain showed general congestion. The other viscera were normal.

\section{Temporary Improvement but Early Death (3 patients)}

Case 2. A boy, aged 4, was greatly improved, both as regards his capacity and his colour, and there would have been no grounds for caution had he not been seen after six months and found to have a much larger heart (c.t.r. 61 to $69 \%$ ). He died two months later with congestive failure.

Case 8. A boy, aged 9, became less cyanosed and for some months was able to get about better but this was at the expense of a larger heart (c.t.r. 63 to $68 \%$ ) and some right-sided congestive failure for his liver became larger and pulsatile. In spite of treatment in hospital the signs of failure could not be reversed and he died after ten months.

Case 17. A boy, aged 9, was equally improved after operation, but his heart also became larger (c.t.r. 54 (Fig. 2B) to $60 \%$ ). He remained well for 18 months when he developed headaches and vomiting and was admitted to hospital elsewhere, gravely ill with meningitis. In spite of treatment he died three weeks later. The purulent exudate over the base of the brain and the cerebellum had spread from an abscess in the left occipital lobe-a condition that seems to be common with all froms of cyanotic congenital heart disease (Campbell, 1957). The middle ears were found to be normal. The heart and lungs were set aside for further examination but were unfortunately lost.

\section{Patients who had Not Tricuspid Atresia (6 Patients)}

In addition to Cases 4 and 27 who had surgical treatment, six other patients, who were thought to have tricuspid atresia on the general picture with varying degrees of left ventricular preponderance, were found to have other malformations. These included pulmonary stenosis with a rotated heart (35), an undeveloped right ventricle (36), a funtional single ventricle (37), cor biloculare (38), and more complex combinations (39 and 40). The last three had necropsies and brief notes of these six follow.

Case 35. A girl, aged 12, had the general picture of tricuspid atresia and also severe kyphosis and the Klipper-Feil syndrome with a webbed neck. After catheterization she was thought to have pulmonary stenosis with a grossly rotated heart and a right-to-left shunt through an unsealed foramen ovale. She was improved by a subclavian-pulmonary anastomosis and is getting on well 9 years later.

Case 36. A man, aged 32, had always been breathless and cyanotic, but managed to work on a farm till he was 31, when he became more short of breath and had hæmoptysis on several occasions. Tricuspid atresia was suspected because of the left ventricular preponderance, but was disproved on catheterization. He had an atrial septal defect, presumably the site of the right-to-left shunt, but a very low pressure, $8 /-3 \mathrm{~mm}$. $\mathrm{Hg}$, in the right ventricle with a normal pressure in the left. The only explanation seemed to be that the right ventricle was underdeveloped and ineffective but he had none of the other features of Ebstein's syndrome.

Case 37. A girl, aged 11, was shown to have a small right-to-left shunt through an unsealed foramen ovale and equal pressures with almost complete mixing of the blood in the two ventricles, i.e. a functionally single ventricle (P143). Her condition remained much the same till a few months before her death, 8 years later: there was no necropsy.

Case 38. A boy, aged 12, was suspected of having tricuspid atresia because of a tendency to left ventricular preponderance. He was proved to have cor biloculare with an unusual type of infundibular stenosis and has been fully reported with a necropsy by Campbell and Jackson (1953).

Case 39. A girl, aged 7, was suspected of having tricuspid atresia because of striking left axis deviation. She died during an attack of unconsciousness and was proved to have a small right ventricle, atrial and ventricular septal defects, infundibular stenosis, partial transposition of the great vessels, a common pulmonary 
vein, and both atrial appendages on the left of the great vessels. She has been fully reported with a necropsy by Dixon (1954).

Case 40 . A girl, aged 2, was cyanotic (hæmoglobin 110-120\%) but not very disabled, as later she could walk half a mile. In view of pleonæmic lungs, an unusual shaped heart with more enlargement of the left than of the right ventricle, and left ventricular preponderance, she was thought to have transposition of the great vessels and tricuspid atresia. In fact, she had neither of these anatomical lesions but unusual malformations that produced similar functional effects. She kept about the same till six years later when she was admitted to Great Ormond Street Hospital with a week's history of malaise and signs of meningitis. A cerebral abscess of the left fronto-parietal lobe was aspirated but she died shortly afterwards.

Necropsy. There was a ragged abscess cavity, $5 \times 6 \times 4 \mathrm{~cm}$., with a well-marked cerebellar pressure cone. The lungs were congested. Except for these and the heart, the other viscera were normal.

The heart was very large, reaching $4.5 \mathrm{~cm}$. to the right and $6.5 \mathrm{~cm}$. to the left. There was a single atrium, measuring $7 \times 5 \times 5 \mathrm{~cm}$. and a single A-V valve. The left vetricle, pear-shaped and measuring 6 by $4 \mathrm{~cm}$., communicated through a V.S.D. with the upper part of the right ventricle. The aortic valve was normal. The large aorta, $2 \cdot 2 \mathrm{~cm}$. in diameter, arose from the left of the left ventricle. The arch was right-sided. The ductus was obliterated.

The main part of the right ventricle, measuring 5 by $4 \mathrm{~cm}$., lay to the right and was completely separated from its upper part by a thick band of muscle so that it was without any outlet or functional place in the circulation. The upper part of the right ventricle, $2 \mathrm{~cm}$. long and $2 \mathrm{~cm}$. wide, was cylindrical and received blood from the left ventricle through the V.S.D. The pulmonary trunk, also $2 \mathrm{~cm}$. in external diameter, arose from this upper part of the right ventricle to the right of the aorta. The pulmonary valve was normal.

\section{Discussion}

Classification. Cases of tricuspid atresia were divided by Kuhne (1906) into those without and those with transposition, and this division has been accepted by most writers. Edwards and Burchell (1949) subdivided the former into those with pulmonary or subpulmonary stenosis (28 cases) and those with pulmonary atresia (4), and the later (with transposition) into those with (8 cases) and those without pulmonary or subpulmonary stenosis (5 cases). In the first group, the obstruction to the pulmonary blood flow was not always due to valvar or infundibular stenosis for unless the ventricular septal defect (V.S.D.) is large (and often it was very small) an adequate amount of blood can not reach the right ventricle on its way to the lungs.

The most important clinical distinction is whether the blood flow to the lungs is diminished or increased, and for this reason the classification of Astley et al. (1953) which follows seems more satisfactory for clinical purposes. The numbers of their cases are given in brackets after each group.

I. Without transposition of the great vessels.

(a) Without pulmonary stenosis. Lungs oligæmic unless V.S.D. is large (3 cases).

(b) With pulmonary stenosis (or atresia). Lungs oligæmic (3 cases).

(c) Presence of pulmonary stenosis uncertain (3 cases).

II. With transposition of the great vessels.

(a) Without pulmonary stenosis. Lungs pleonæmic but systemic flow may be poor (4 cases).

(b) With pulmonary stenosis. Lungs generally oligæmic, but blood flow may be satisfactory or even too large if the stenosis is slight ( 3 cases).

Most of our patients belonged to Group I (without transposition). Edwards and Burchell (1949) found 77 per cent of their patients in Group I and found that less than one-fifth of them reached the age of 2 years. It seems, therefore, that our older patients, although most of them have done so badly, must have been the survivors of a much larger number.

None of our patients were proved to have transposition without pulmonary stenosis (Group IIa) but Case 12, who died when he was 7, may have had, since he had coarctation of the aorta also. Macafee and Patterson (1961), discussing 14 cases ( 3 of their own and 11 reported), found coarctation in 8 of the 14: only 3 of the 14 lived for more than six months and they died at the ages of 2,4 , and 6 years respectively.

Only one of our patients had transposition with pulmonary stenosis (Group IIb) (Case 15, proved by necropsy). Case 27 was, however, shown to have corrected transposition with other malformations after a second angiocardiogram. 
Patients who have Done Well. Three of our patients got on unusually well without operation: they were boys, aged 8,12 , and 18 respectively. Perhaps Case 5, the boy of 19 who has done exceptionally well after operation, was really one of these patients who would have done fairly well in any case, for he was much less disabled than most of those who had an operation. Probably it is chance that these were all boys but not chance that they were older than the others when they were first seen, since the unusual patient who has passed the hazards of infancy and early childhood has a better expectation of continuing his good progress.

Presumably the small number of patients who do well have (1) a ventricular septal defect that is large enough to allow an adequate blood flow to the lungs through the small right ventricle, or (2) transposition of the pulmonary trunk to the left ventricle with pulmonary stenosis of a degree that prevents pleonæmia of the lungs but yet allows an adequate blood flow. Edwards and Burchell found prognosis least bad in the last group.

Surgical Treatment. In all these groups except IIa, the lungs are generally oligæmic and the patient can be helped by an anastomotic operation. More rarely, in Group IIb, he can be helped by pulmonary valvotomy, but then the valve opening must not be made too large or the lungs will become pleonæmic and any improvement may not last long. The operation was a subclavianpulmonary anastomosis in all our patients except Case 4 who had pulmonary valvotomy.

As described earlier, several of them obtained results that were comparable with those obtained for Fallot's tetralogy. Case 5 has maintained an exceptionally good result for more than ten years and six others are still doing well. Two others were much better for six years until their relapse and subsequent deaths. These results provide a striking contrast with the very high mortality of those who had no operation and suggest that more patients should have had an operation, even if the general level of improvement is not quite as great as in those with Fallot's tetralogy.

Cases 2 and 8 died with congestive heart failure within a year of their operations, although they had been able to do much more and were much less cyanotic. The enlargement of the liver and the onset of right-sided failure in these two patients suggest that the right atrium found it difficult to get rid of the blood returned to it, perhaps because the defect of the atrial septum was too small. But there is no obvious reason why the amount of blood returned to the right atrium should have been increased by a successful operation. It was unfortunate that these two, who were among the earliest patients operated on, had such large hearts (the only ones with a c.t.r. of $60 \%$ or over), for this may have been the main reason for their failure and death, and for making me think that, with so many patients waiting for operation, those with Fallot's tetralogy should have preference as likely to obtain more lasting benefit.

The difference between these two and the successful cases can be only partly due to the larger hearts, since Cases 18 and 20 each had a heart that was nearly as large (see Table II). At first we were anxious about these two because of their large hearts, but Case 20 has done well for ten years, although the heart became larger, and in Case 18 who also has done well it became smaller after operation. It seems that the heart size is some guide as to whether a patient with tricuspid atresia can be given a good expectation of lasting improvement after operation; if the cardiothoracic ratio is no more than 55 per cent, there is a good chance of a successful result that will last at any rate for several years; but if it is 60 or more there seems to be a risk of congestive heart failure in spite of improvement at first, and at the least the parents must be warned that a lasting good result can not be promised. The figures are too small for this to be accepted without wider experience, but it seems likely to prove correct.

Taussig et al. (1951) also obtained many good results, though with a higher mortality than for Fallot's tetralogy, both at the time of operation and in the first six months after when it was 26 per cent. In their later follow-up (White et al., 1956) several still maintained their improvement but again there were more relapses and deaths. It is, therefore, surprising that Brown et al. (1956) were so disappointed with their results, all three patients dying soon after: they thought, because the muscular arteries and veins showed extensive vascular clotting, that the lungs were unable to deal with the increased blood flow, but this has not been our experience. 
In view of the very high mortality of those who did not have an operation, it seems that all patients with tricuspid atresia, except the small number who have little disability, should be given the chance of a great improvement from an anastomotic operation, until the time comes when a more curative operation is available.

\section{Summary AND CONCLUSIONS}

Forty patients with a clinical diagnosis of tricuspid atresia have been reviewed. In one-fifth of them, this diagnosis, based mainly on central cyanosis with left ventricular preponderance in the electrocardiogram and on radioscopy, proved wrong. Angiocardiography generally provided the best confirmation. Their clinical features have been reviewed.

Surgical treatment was carried out in 12 patients, of whom 7 are still greatly improved after seven to ten years, 2 did well for six years but then lost ground and died within a few years, and 3 died within a year or so. Only two of these 7 (Cases 5 and 20) have reached the age when they have shown that they can carry on a reasonably normal quiet life at work.

The prognosis of the other 28 patients proved extremely bad as 20 of them $(71 \%)$ are known to have died. All but 5 of these died within two years of being first seen and only one lived for more than six years. Clearly the bad prognosis that is recognized in infancy continues throughout childhood. Very few patients have a blood flow to the lungs that is adequate yet not too large. This may, however, happen when the ventricular septal defect is big enough to allow an adequate flow to the right ventricle that can receive it and pass it on to the lungs without further obstruction, or when the pulmonary trunk arises from the left ventricle and a suitable degree of pulmonary stenosis protects the lungs from too large a blood flow and yet allows an adequate flow.

With the advance in open-heart surgery, these considerations must be borne in mind in planning a more fundamental improvement in the circulation through the heart. In the meantime, the bad prognosis suggests that all patients with tricuspid atresia, except the few with only slight disability and cyanosis, should be given the chance of a subclavian-pulmonary anastomosis: this certainly improves their capacity and prognosis, though generally less than in Fallot's tetralogy.

It is a pleasure to thank Sir Russell Brock and Mr. Holmes Sellors for operating on twelve of these patients. I am grateful to Dr. Deuchar for many of the catheter results and for giving me the opportunity of a final follow-up of most of these patients during the last year.

\section{REFERENCES}

Abbott, M. E. (1936). Atlas of Congenital Heart Disease. American Heart Association, New York. Astley, R., Oldham, J. S., and Pearsons, C. G. (1953). Brit. Heart J., 15, 287.

Brown, J. W. (1936). Arch. Dis. Childh., 11, 275.

-, Heath, D., Morris, T. L., and Whitaker, W. (1956). Brit. Heart J., 18, 499.

Campbell, M. (1953). Brit. Heart J., 15, 462.

- (1954). Brit. Heart J., 16, 284.

- (1957). Lancet, 1, 111.

- (1958a). Brit. Heart J., 20, 253.

- (1958b). Brit. Heart J., 2, 1178.

—

—, and Deuchar, D. C. (1953). Brit. med. J., 1, 349.

- , and Jackson, J. W. (1953). Guy's Hosp. Rep., 102, 337.

Dixon, A. St. J. (1954). Brit. Heart J., 16, 153.

Edwards, J. E., and Burchell, H. B. (1949). Med. Clin. N. Amer., 33, 1175.

Kuhne (1906). Quoted by Edwards and Burchell (1949).

Macafee, C. A. J., and Patterson, G. C. (1961). Brit. Heart J., 23, 308.

Neill, C. A., and Brink, A. J. (1955). Circulation, 12, 612.

Scott, G. W. (1955). Guy's Hosp. Rep., 104, 67.

Spear, G. S. (1960). Bull. Johns Hopk. Hosp., 106, 347.

Taussig, H. B. (1936). Bull. Johns Hopk. Hosp., 59, 435.

, King, J. T., Bauerfeld, R., and Padvamoti-Iyer, S. (1951). Trans. Ass. Amer. Phycns., 64, 67.

Vela, J., Espino, Bernard, R., Portillo, B., Quiroga, R., and Rubio, V. (1958). Arch. Inst. Cardiol., $28,28$.

White, B. D., McNamara, D. G., Bauerfeld, S. R., and Taussig, H. B. (1956). Circulation, 14, 512.

Wood, Paul (1956). Diseases of the Heart and Circulation. 2nd ed. Eyer and Spottiswoode, London. 